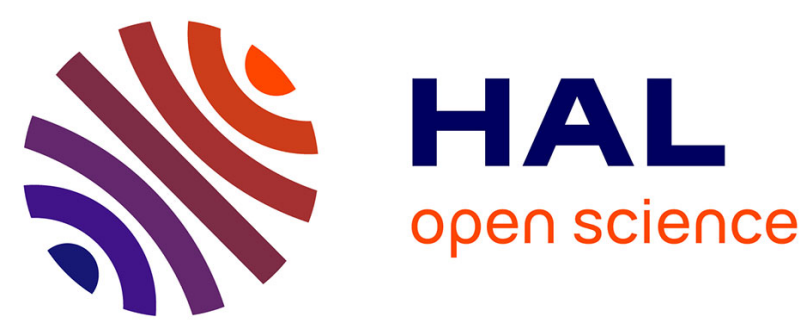

\title{
Improved electro-grafting of nitropyrene onto onion-like carbon via in situ electrochemical reduction and polymerization: tailoring redox energy density of the supercapacitor positive electrode
}

Bihag Anothumakkool, Pierre-Louis Taberna, Barbara Daffos, Patrice Simon, Yuman Sayed-Ahmad-Baraza, Chris P. Ewels, Thierry Brousse, Joel Gaubicher

\section{- To cite this version:}

Bihag Anothumakkool, Pierre-Louis Taberna, Barbara Daffos, Patrice Simon, Yuman Sayed-AhmadBaraza, et al.. Improved electro-grafting of nitropyrene onto onion-like carbon via in situ electrochemical reduction and polymerization: tailoring redox energy density of the supercapacitor positive electrode. Journal of Materials Chemistry A, 2017, vol. 5 (n 4), pp. 1488-1494. 10.1039/C6TA08170C . hal-01581163

\author{
HAL Id: hal-01581163 \\ https://hal.science/hal-01581163
}

Submitted on 4 Sep 2017

HAL is a multi-disciplinary open access archive for the deposit and dissemination of scientific research documents, whether they are published or not. The documents may come from teaching and research institutions in France or abroad, or from public or private research centers.
L'archive ouverte pluridisciplinaire HAL, est destinée au dépôt et à la diffusion de documents scientifiques de niveau recherche, publiés ou non, émanant des établissements d'enseignement et de recherche français ou étrangers, des laboratoires publics ou privés. 


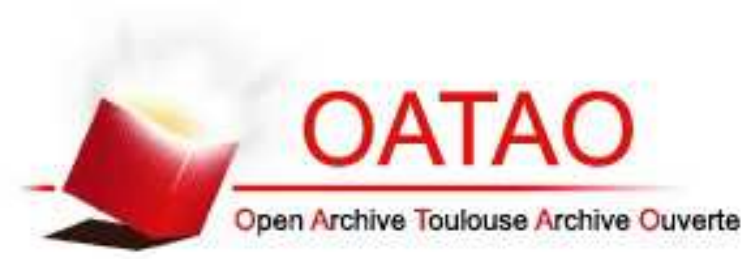

\section{Open Archive TOULOUSE Archive Ouverte (OATAO)}

OATAO is an open access repository that collects the work of Toulouse researchers and makes it freely available over the web where possible.

This is an author-deposited version published in : http://oatao.univ-toulouse.fr/ Eprints ID : 18011

To link to this article : DOI: $10.1039 / \mathrm{C} 6 \mathrm{TA} 08170 \mathrm{C}$

URL : http://dx.doi.org/10.1039/C6TA08170C

To cite this version : Anothumakkool, Bihag and Taberna, PierreLouis and Daffos, Barbara and Simon, Patrice and Sayed-AhmadBaraza, Yuman and Ewels, Chris P. and Brousse, Thierry and Gaubicher, Joel Improved electro-grafting of nitropyrene onto onion-like carbon via in situ electrochemical reduction and polymerization: tailoring redox energy density of the supercapacitor positive electrode. (2017) Journal of Materials Chemistry. A, vol. 5 $\left(\mathrm{n}^{\circ} 4\right)$. pp. 1488-1494. ISSN 2050-7488

Any correspondence concerning this service should be sent to the repository administrator: staff-oatao@ listes-diff.inp-toulouse.fr 


\title{
Improved electro-grafting of nitropyrene onto onion-like carbon via in situ electrochemical reduction and polymerization: tailoring redox energy density of the supercapacitor positive electrode $\uparrow$
}

\begin{abstract}
Bihag Anothumakkool, ${ }^{a}$ Pierre-Louis Taberna, ${ }^{\text {bc }}$ Barbara Daffos, ${ }^{\text {bc }}$ Patrice Simon, ${ }^{\text {bc }}$ Yuman Sayed-Ahmad-Baraza, ${ }^{a}$ Chris Ewels, ${ }^{a}$ Thierry Brousse ${ }^{* a c}$ and Joel Gaubicher ${ }^{* a}$

Herein, we report an improved method for the physical grafting of 1-nitropyrene (Pyr- $\left.\mathrm{NO}_{2}\right)$ onto highly graphitized carbon onion. This is achieved through a lowering of the onset potential of the pyrene polymerization via in situ reduction of the $\mathrm{NO}_{2}$ group. The additional redox activity pertaining to the reduced $\mathrm{NO}_{2}$ enables exceeding the faradaic capacity, which is associated with the p-doping of the grafted pyrene backbone, as observed for pyrene, 1-aminopyrene, and unreduced Pyr- $\mathrm{NO}_{2}$. Theoretical calculations demonstrate the charge transfer and binding enthalpy capabilities of Pyr- $\mathrm{NO}_{2}$, which are significantly higher than those of the other two species, and which allow for improved $\mathrm{p}$-stacking on the carbon surface. Upon $20 \mathrm{wt} \%$ grafting of Pyr- $\mathrm{NO}_{2}$, the capacity of the electrode jumps from $20 \mathrm{~mA} \mathrm{~h}$ gelectrode $^{-1}$ to $38 \mathrm{~mA} \mathrm{~h}$ gelectrode ${ }^{-1}$, which corresponds to $110 \mathrm{~mA} \mathrm{~h} \mathrm{~g}{ }^{-1}$ per mass of Pyr $-\mathrm{NO}_{2}$ and the average potential is increased by $200 \mathrm{mV}$. Very interestingly, this high performance is also coupled with outstanding retention with respect to both the initial capacity for more than 4000 cycles, as well as the power characteristics, demonstrating the considerable advantages of employing the present in situ grafting technique.
\end{abstract}

\section{Introduction}

Highly efficient electrochemical energy storage devices are an integral part of renewable energy technology, as they smooth out its intermittent nature by effective storage and delivery. ${ }^{1,2}$ Among such devices, supercapacitors ${ }^{3}$ in comparison to Li-ion batteries show superior power density, excellent shelf life, high coulombic efficiency etc., which makes them an ideal candidate for high-power applications. However, the low energy density ( $\sim 5-8 \mathrm{~W} \mathrm{~h} \mathrm{~kg}^{-1}$ ) of conventional electrochemical double-layer capacitors (EDLC) ${ }^{2,4}$ is a key issue with respect to hindering their use in a higher energy bracket. Molecular redox grafting ${ }^{5-12}$ is one of the strategies currently used to enable higher energy performance, while the other consists in tailoring the micropore size. ${ }^{13}$ Indeed, the faradaic processes associated with redox grafting convey both higher charge storage and a higher average

anstitut des Materiaux Jean Rouxel (IMN), University of Nantes, CNRS, 2, rue de Houssiniere-B.P. 32229-44322, Nantes cedex 3, France. E-mail: joel.gaubicher@ cnrs-imn.fr; thierry.brousse@univ-nantes.fr

${ }^{b}$ Universite Paul Sabatier, Cirimat/Lcmie, 31062 Toulouse cedex 9, France 'Réseau sur le Stockage Electrochimique de l'Energie (RS2E), FR CNRS 3459, France $\dagger$ Electronic supplementary information (ESI) available. See DOI: $10.1039 / \mathrm{c} 6 \mathrm{ta} 08170 \mathrm{c}$ voltage. In this regard, conducting polymers, ${ }^{14}$ as well as various metal-based oxide compounds, ${ }^{15}$ are considered to be potential alternative materials as many of them show relativity high redox capacity. However, most of these materials only show superior electro-chemical properties in aqueous electrolytes, which severely restrict the potential window and, therefore, the final energy density of the supercapacitor. One of the main reasons for these additives not being particularly efficient in organic media (they only convey higher charge transfer capacity) pertains to the value of their redox potential, which lies in the middle of the electrochemical window of the electrolyte.

Thus, the selection of materials possessing more extreme redox potentials, along with high capacity and cycling stability, are essential criteria for achieving competitive performance. As is the case of (2,2,6,6-tetramethylpiperidin-1-yl)oxyl (TEMPO), many organic centers show ideal redox activity in non-aqueous media $^{16}$ however, they presently require a polymer backbone, which shows low conductivity, and thereby restricts the use of these TEMPO derivatives to either low-power applications or low surface capacity thin-film electrodes. ${ }^{17}$ Moreover, the final cost of the device and availability of the material often prove detrimental to widespread use, which is a major concern with respect to the above molecules as they require extensive synthetic chemistry. 
Pyrene, one of the polycyclic aromatic compounds, is known for its stable redox chemistry in a polymerized state at an ideal potential, and thus for its propensity to serve as positive electrode..$^{18}$ Additionally, pyrene derivatives develop $\pi$-stacking type interactions, especially on graphitic carbon, and can be further polymerized to form a p-doped conducting polymer via simple electrochemical methods. Our group recently reported a strategy for in situ grafting (here onwards the term grafting indicate the non covalent $\pi$ stacking of pyrene molecules) of such pyrene derivatives onto a carbon fiber electrode using a conventional electrolyte. ${ }^{6}$ This approach offers enormous advantages with respect to upscaling considerations because it does not impose any change in electrode chemistry protocols, as opposed to those incurred by ex situ chemistries involving pyrene units, as reported by other researchers. ${ }^{19}$ Considering that the adsorption ${ }^{20}$ of polycyclic pyrene from the electrolyte is driven by $\pi-\pi$ interactions, the graphitization state of the carbon substrate ${ }^{21}$ is obviously a critical parameter. Among the various types of carbon ${ }^{4}$ utilized for the EDLC, carbon onions/ onion-like carbons (OLCs) ${ }^{22}$ are known for exhibiting a pore size distribution in the mesoporosity range (2-12 $\mathrm{nm})$, arising from the voids between the particles. They possess highly graphitized graphene layers arranged in spherical onion-like structures of 5-10 nm particles with a relatively high specific surface area (SSA, $640 \mathrm{~m}^{2} \mathrm{~g}^{-1}$ ). Furthermore, even though they show fairly low capacitance $\left(\sim 30 \mathrm{~F} \mathrm{~g}^{-1}\right),{ }^{23}$ they are widely recognized for their high power capability,,$^{24,25}$ in contrast to activated carbons that possess an amorphous surface and a tortuous micropore network. Indeed, as inferred from the Bruggeman Model, ${ }^{26,27}$ depending on the electrolyte conductivity, the high tortuosity of the carbon may be a reason for limited mass transport. Another distinct advantage of OLCs concerns their pack density (1.5-2.3 $\left.\mathrm{g} \mathrm{cm}^{-3}\right)$, which is much higher than that of graphene $\sim 0.069 \mathrm{~g} \mathrm{~cm}^{-3},{ }^{28}$ and even that of conventional activated porous carbon ( 0.5 to $\left.0.7 \mathrm{~g} \mathrm{~cm}^{-3}\right)$. For these reasons, OLC appears to be an ideal material for the present redox molecular grafting strategy. Thus, taking these considerations in account, this article presents a method for doubling the capacity of a highly graphitic OLC sample, without degrading its power capabilities,

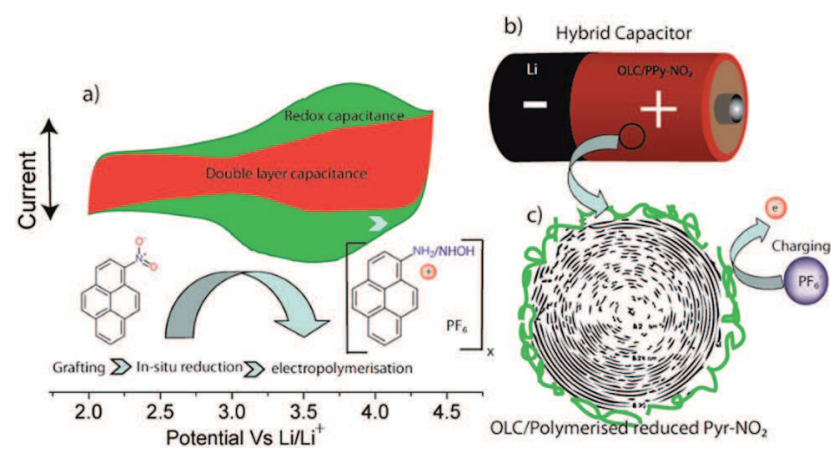

Scheme 1 1(a) Added redox capacity from 1-nitropyrene over EDLC of OLC represented in cyclic voltammetry profile; transformations of the same molecule in during cell cycling. (b) Representation of the hybrid capacitor combination and (c) schematics of OLC grafted with the polymerized pyrene. by means of the controlled in situ grafting of various pyrene derivatives. During in situ reduction and polymerization, 1-nitropyrene is shown to play a pivotal role in developing high energy density positive electrodes for supercapacitors (Scheme 1).

\section{Experimental section}

\section{Materials}

Pyrene, 1-aminopyrene, 1-nitropyrene were purchased from Aldrich Chemicals, LP-30 from BASF, and nanodiamond (>97\%) from PlasmaChem.

\section{Synthesis of carbon onion}

Commercial nanodiamond powder underwent a thermal treatment under vacuum in a graphite micro-furnace. A heating rate of $100{ }^{\circ} \mathrm{C} \mathrm{min}^{-1}$ was used to attain a final temperature of $2000{ }^{\circ} \mathrm{C}$. The dwell time applied was 30 minutes.

\section{In situ electrografting}

A Bio-Logic VMP-2 or -3 was used for all of the electrochemical characterizations. Li metal was used as the reference and counter electrode. All the potentials mentioned hereafter were measured with either a $\mathrm{Li} / \mathrm{Li}^{+}$reference electrode or with another reference electrode detailed in the corresponding paragraph. In situ grafting was carried out by electro-chemical polymerization in a 3-electrode Swagelok cell by cyclic voltammetry at a scan rate of $5 \mathrm{mV} \mathrm{s}^{-1}$ in the potential range of 2 to $4.4 \mathrm{~V}\left(v s . \mathrm{Li} / \mathrm{Li}^{+}\right)$. The electrolyte solution consisted of a mixture of pyrene (Pyr), 1-nitropyrene $\left(\mathrm{Pyr}-\mathrm{NO}_{2}\right)$ or 1-aminopyrene (Pyr- $\mathrm{NH}_{2}$ ) in LP-30. Electrochemical impedance (EIS) analysis was conducted from $100 \mathrm{KHz}$ to $0.01 \mathrm{~Hz}$ against the open circuit potential with a sinus amplitude of $10 \mathrm{mV}\left(V_{\text {rms }}=7.07 \mathrm{mV}\right)$. Charge-discharge cycling was performed between 1.5-4.4 V ( $v s . \mathrm{Li} / \mathrm{Li}^{+}$) with various current densities. The amount of grafted molecules was quantified using UV-visible spectroscopy (Perkin-Elmer Lambda 1050 with 3D WB detector module), by calibrating the characteristic peaks of pyrene in LP-30 electrolyte before and after in situ grafting. Scanning electron microscopy (SEM) and transmission electron microscopy (TEM) were carried out in Jeol JSM-7600F and Hitachi H9000NAR microscopes $\left(300 \mathrm{kV}, \mathrm{LaB}_{6}\right.$, point to point resolution = $0.18 \mathrm{~nm})$, respectively.

\section{Density functional theory (DFT) calculations of pyrene and its derivatives}

DFT calculations were performed on large 128-atom hexagonal $8 \times 8$ graphene cells, with a $4 \times 4 \times 1 k$-point grid, using a $0.04 \mathrm{eV}$ Fermi smearing function for the electron temperature to aid self-consistent convergence. Interlayer spacing was set to over $12 \AA$ to avoid interaction with neighboring sheets. Charge density was constructed on a real-space grid with an energy cutoff of $175 \mathrm{Ha}$ (200 Ha when oxygen present), while Kohn-Sham wave functions were constructed using localized Gaussianbased orbital functions (38/12/40/40 for $\mathrm{C} / \mathrm{H} / \mathrm{O} / \mathrm{N}$ respectively, up to maximum angular momentum $l=2$ ). All atoms were fully 
optimized using a conjugate gradient algorithm. Atomic charge states were calculated using Mulliken population analysis.

\section{Result and discussion}

Prior to electrochemical polymerization, all cells were kept in open-circuit potential (OCP) for 12 hours in order to ensure proper $\pi$-stacking of monomers onto the host OLC. Whenever the molecular grafting of a carbon surface is involved, a recurring issue arises relative to its impact on the electrical properties of the substrate. During OCV, it is instructive to trace the evolution of the charge transfer resistance $\left(R_{\mathrm{ct}}\right)$ from EIS before and after the introduction of 1-nitropyrene $\left(\mathrm{Pyr}-\mathrm{NO}_{2}\right)$ into the LP-30 electrolyte. As shown in Fig. 1a, even in pure LP-30, there is a slight increase in the $R_{\mathrm{ct}}$, which could be tentatively ascribed to the interaction between solvated ions from the electrolyte and electrons in the vicinity of the carbon surface. ${ }^{29}$ However, after the introduction of Pyr- $\mathrm{NO}_{2}$, a significant increase in the charge transfer resistance (Fig. 1a) is observed, indicating a possible electron trapping effect that could arise from polar Pyr- $\mathrm{NO}_{2}$ molecules interacting with the OLC surface through $\pi$-stacking. ${ }^{30}$ This molecular surface coverage can then serve to provide a partial definition of the potential of the working electrode from the redox potential of the molecule $\left(\mathrm{Pyr}-\mathrm{NO}_{2}\right.$ around $2.0 \mathrm{~V}$ vs. $\mathrm{Li} / \mathrm{Li}^{+}$). Such surface grafting interactions are confirmed by the sharp $100 \mathrm{mV}$ drop in OCV upon the addition of molecules to the medium (Fig. 1a). As expected, such a drop was absent in case of softer carbon (YP-80), which demonstrates poor grafting, thus indicating that the OCV drop relates to the grafting of Pyr- $\mathrm{NO}_{2}$ (ESI Fig. S1a†). To rule out the possibility of $\mathrm{Li}$ or electrolyte interactions with the Pyr- $\mathrm{NO}_{2}$ being responsible for the drop in OCV, an experiment was also carried out in acetonitrile/ $/ \mathrm{TEABF}_{4}$ using an $\mathrm{Ag} / \mathrm{AgCl}$ reference electrode and a stainless steel counter electrode (Fig. S1b †). A similar drop in
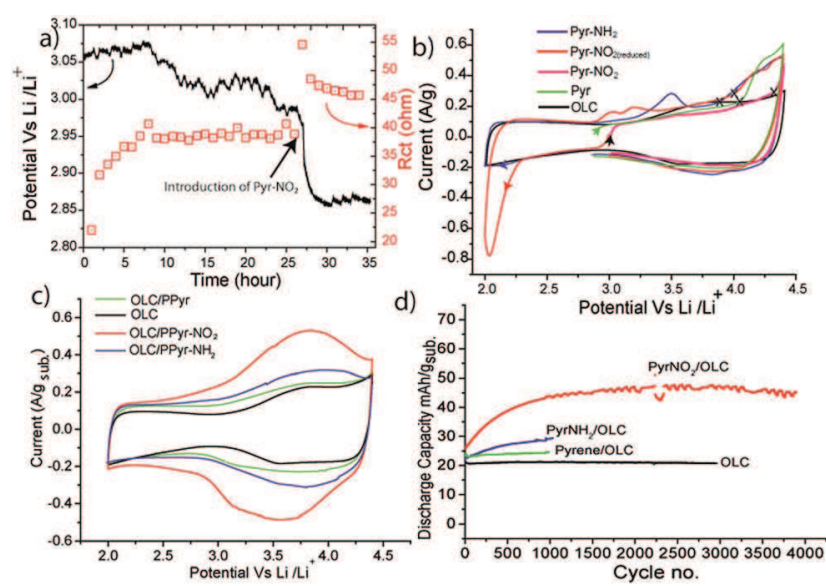

d) 70

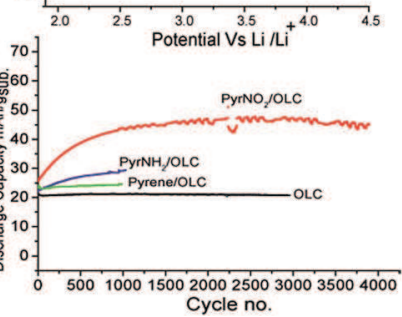

Fig. 1 (a) Charge transfer resistance (calculated from EIS spectra) and open circuit potential of OLC electrode in LP-30 for $26 \mathrm{~h}$, and further after the introduction of $2 \mathrm{mM} \mathrm{Pyr}-\mathrm{NO}_{2}$ in LP-30. (b) $1^{\text {st }}$ and (c) $1000^{\text {th }}$ $\mathrm{CV}$ profile at a scan rate of $5 \mathrm{mV} \mathrm{s}^{-1}$ in LP-30 containing $2 \mathrm{mM}$ pyrene or its derivates; the ' $x$ ' indicates the onset of polymerization. (d) The discharge capacity of OLC between 2-4.4 V during the continuous CV cycles carried out at $5 \mathrm{mV} \mathrm{s}^{-1}$ in various pyrene samples in LP-30.
OCV and increase in $R_{\mathrm{ct}}$ was observed, which ruled out the possible role of both $\mathrm{Li}$ and electrolyte, and thereby confirmed the interaction of the OLC with Pyr- $\mathrm{NO}_{2}$. The OCV subsequently stabilizes after approximately 90 minutes, indicating that the Pyr- $\mathrm{NO}_{2}$ adsorption is fairly rapid at room temperature. In order to gain further insight into the adsorption kinetics, in situ UV-visible spectroscopy (Fig. S2†) was conducted in the LP-30 for 14 hours. Although all molecules clearly show adsorption onto the graphitic OLC, the extent of that of the Pyr- $\mathrm{NO}_{2}$ appears to be slightly higher. This higher affinity stems presumably from the high polarity of the Pyr- $\mathrm{NO}_{2}$. A simple mixing of OLC with Pyr- $\mathrm{NO}_{2}$ in LP-30 shows a $13 \mathrm{wt} \%$ uptake maximum over 7 days, which is much higher than that of Pyr (6.5 wt\%) and Pyr- $-\mathrm{NH}_{2}$ (4.3 wt\%). The number of moles of Pyr- $\mathrm{NO}_{2}$ on the OLC surface is found to be $9.25 \times 10^{-5}$ moles $\mathrm{cm}^{-2}$. This value indicates multilayer $\pi$ stacking by considering the geometrical area of the molecules as $189 \AA^{2}$.

After the physical grafting, the electrodes underwent electrochemical polymerization in the same cell, i.e. an LP-30 containing $2 \mathrm{mM}$ pyrene derivatives with Li metal as the counter and reference electrode. Fig. $1 \mathrm{~b}$ shows the initial $\mathrm{CV}$ profile at a scan rate of $5 \mathrm{mV} \mathrm{s}^{-1}$ for a $5 \mathrm{mg} \mathrm{cm}{ }^{-2}$ electrode. Given that all the present pyrene derivatives have nearly the same surface (189, 212 and $200 \AA^{2}$ for Pyr, Pyr- $-\mathrm{NO}_{2}$ and $\mathrm{Pyr}-\mathrm{NH}_{2}$ respectively) available for radical stabilization through delocalization, the onset oxidation potential is expected to vary according to the Hammett constant, which relates to both the electron donating or withdrawing ability and resonance stabilization effects of the substituent. ${ }^{19}$ The latter is 0.78 for $-\mathrm{NO}_{2}$ and -0.66 for $\mathrm{NH}_{2} \cdot{ }^{31}$ Accordingly, the onset potential for polymerization $\left(v s . \mathrm{Li} / \mathrm{Li}^{+}\right)$ was found to decrease in the following order: $\mathrm{Pyr}_{-} \mathrm{NO}_{2}(4.33 \mathrm{~V})>$ Pyr $(4.06 \mathrm{~V})>$ Pyr- $\mathrm{NH}_{2}(3.86 \mathrm{~V})$. Upon oxidative electro-polymerization, the resulting polymer (oligomer) undergoes subsequent p-doping counterbalanced by the mass transport of $\mathrm{PF}_{6}{ }^{-}$ anions within its porosity, in the vicinity of $3.7 \mathrm{~V}$ (Fig. 1c). ${ }^{32}$ However, it is worth noting that the corresponding faradaic capacity is directly superimposed onto that of the double layer, without any significant alteration to the latter. Another advantage of using pyrene derivatives lies in its versatility with respect to the choice of possible functionalization. In particular, redox units can still further enhance the faradaic capacity. ${ }^{6}$ In the present work, we have investigated the role of the $\mathrm{NO}_{2}$ group, which can undergo reduction below $2.4 \mathrm{~V}$ through various mechanisms to form either amino or nitro radical anion, or hydroxylamine, depending on the electrolytic medium. ${ }^{33}$ In order to investigate the effect of $\mathrm{NO}_{2}$ reduction on the electropolymerization mechanism, a cell containing $2 \mathrm{mM}$ Pyr- $\mathrm{NO}_{2}$ in the electrolyte was biased in the negative direction, which indeed caused a reduction of the nitro group at a potential of around $2.3 \mathrm{~V}$ (Fig. 1b). The product formed upon the first reduction of the nitro group is mainly hydroxylamine, ${ }^{34}$ which is calculated using the integrated capacity below the peak at $2.2 \mathrm{~V}$. This will further oxidized by losing $2 \mathrm{e}^{-}$at $3.2 \mathrm{~V}$ in the subsequent $\operatorname{scan}^{35}$ (Fig. S3 in ESI $\dagger$ ). The latter has a direct impact on the onset of the oxidative polymerization potential, which is lowered by approximately $33 \mathrm{mV}$ in the preceding +ve scan. Such a change in the potential facilitates the polymerization 
Table 1 Summary of DFT calculations of pyrene and pyrene derivatives on a graphene surface

\begin{tabular}{lll}
\hline & $\begin{array}{l}\text { Charge transfer from } \\
\text { graphene per molecule in electrons }\end{array}$ & $\begin{array}{l}\text { Binding enthalpy between } \\
\text { molecule and graphene surface (eV) }\end{array}$ \\
\hline Pyrene (Pyr) & 0.01 & 0.720 \\
from moiety to surface (angstroms)
\end{tabular}

current which is found to be nearly 4 times higher in case of reduced $-\mathrm{NO}_{2}\left(12 \mathrm{C} \mathrm{g}^{-1}\right)$ compared to unreduced $-\mathrm{NO}_{2}\left(3 \mathrm{C} \mathrm{g}^{-1}\right)$. However, the hydroxylamine is further reduced to amino during the ensuing cycles (the $2^{\text {nd }}$ cycle is given Fig. S3 in ESI $\dagger$ ). The proton associated with the formation of the hydroxylamine and amino group could possibly arise from the traces of water, the impurity, present in the LP-30 (20 ppm, which is $1.3 \mathrm{mM}$ under our conditions). A more realistic assumption, however, would be to consider the effect of the protons released during oligomerization/polymerization of the pyrene unit $\left(2 \mathrm{H}^{+}\right.$per pyrene would correspond to $8 \mu \mathrm{M}$ under our conditions). ${ }^{30}$ Whichever the case may be, the nitro group certainly allows for an unprecedented improvement of the OLC capacity, and one which vastly exceeds that of $\mathrm{Pyr}-\mathrm{NH}_{2}$ and Pyr while cycling between 2-4.4 V (Fig. 1d). A comparative CV profile of the $1000^{\text {th }}$ cycle is shown in Fig. 1c.

In order to further clarify the interaction between the carbon surface and pyrene molecules, DFT calculations of pyrene and its derivatives were performed. Given the large diameter of the carbon onions, local curvature effects on the external surface are negligible, and local molecular-surface interactions can be dealt with using graphene as a model for the surface. All three species (Pyr, Pyr- $\mathrm{NO}_{2}$ and Pyr- $\mathrm{NH}_{2}$ ) bind to the graphene and demonstrate charge transfer from the graphene to the molecules (see Table 1). In all cases, the most stable structure is one where the pyrene moiety is parallel to the graphene surface, thereby maximizing $\pi$-stacking interactions. The binding energy is largely independent of the precise molecular position (with a slight preference for $\mathrm{AB}$ stacking) suggesting that the molecules should be surface-mobile. Nonetheless, there are significant differences in their responses. Notably, both charge transfer and binding for Pyr- $\mathrm{NO}_{2}$ is significantly higher than for the other two species (see Table 1), and which are consistent with experimental data obtained in the electrochemical and adsorption experiments (UV-visible studies). This is also reflected by its location, which is significantly closer to the graphene surface by comparison to the other two, and indeed results in slight distortion of the graphene basal plane, as can be seen in Fig. 2. It should be noted that these calculations do not incorporate interactions with localized defects and impurities, which are likely to result in still higher binding energies. Additionally, if the molecules are able to migrate into positions lying between neighboring sheets (neighboring carbon onions in the experiment), one would expect a further increase in binding and associated charge transfer.

Post-mortem analysis of electrodes was carried out using SEM. Fig. 3a shows an image of the bare OLC. After in situ

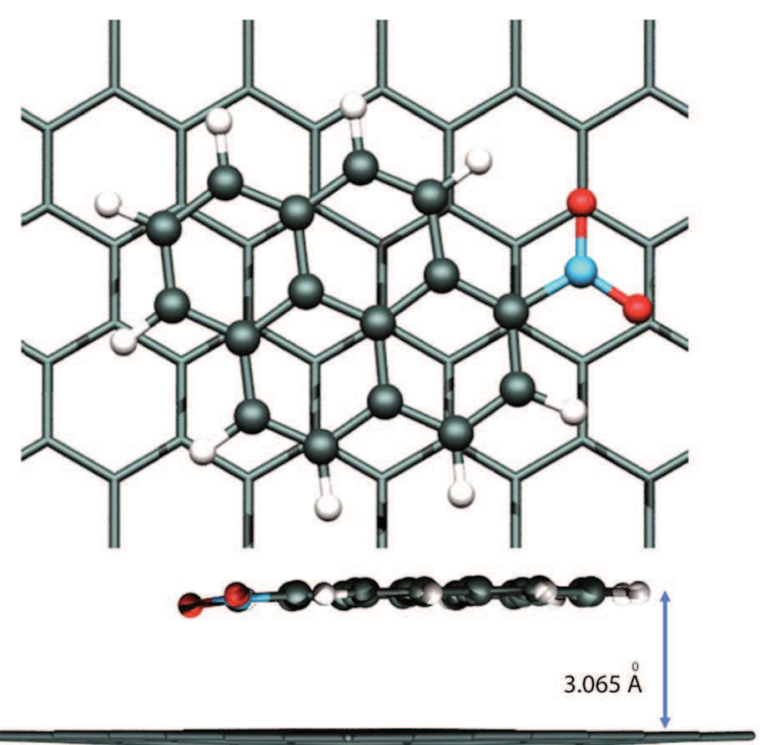

Fig. 2 Stable AB-stacked orientation of 1-nitropyrene on the graphene surface.

polymerization of Pyr- $\mathrm{NO}_{2}$ from LP-30 onto the carbon electrode (referred to as $\mathrm{OLC} / \mathrm{PPy}-\mathrm{NO}_{2}$ ), the surface of the OLC is uniformly covered by the Pyr- $\mathrm{NO}_{2}$, as is evident from Fig. $3 \mathrm{~b}$. The $\mathrm{wt} \%$ of polymer in this example is nearly $30 \mathrm{wt} \%$, as inferred from UV-visible spectroscopy. Although the TEM observation of OLC (Fig. 3c) allows for a clear depiction of the graphitic layers of the OLC before polymerization, the heavy polymer coverage prevents from a thorough characterization of the OLC/PPy- $\mathrm{NO}_{2}$ surface (Fig. 3d). Further, XPS spectra unambiguously prove the reduction of $\mathrm{NO}_{2}$ groups. The nitrogen 1s spectrum of the polymerized electrode is shown in Fig. 4a (N1s of pure Pyr- $\mathrm{NH}_{2}$ and Pyr- $\mathrm{NO}_{2}$ is shown in ESI Fig. S4 $\dagger$ ). Binding energy (BE) of N1s is reduced from $406.3 \mathrm{eV}$ $\left(-\mathrm{NO}_{2}\right)$ to $400.6 \mathrm{eV}$ in the case of OLC/PPyr- $\mathrm{NO}_{2}$, which can deconvoluted into two peaks issuing from $-\mathrm{NHOH}(402.2 \mathrm{eV})$ and $-\mathrm{NH}_{2}(400.4 \mathrm{eV}){ }^{36}$ The presence of a strong $-\mathrm{NH}_{2}$ peak also confirms the conversion of $\mathrm{NHOH}$ formed upon the first cycle to $-\mathrm{NH}_{2}$ during the remaining cycles. Raman spectra (Fig. 4b) reconfirm the results obtained in the microscopy analysis. Spectra show typical D, G and 2D bands for the OLC as expected at wavelengths of 1335,1571 and $2675 \mathrm{~cm}^{-1}$, respectively. ${ }^{37}$ Pure PPyr- $\mathrm{NO}_{2}$, however, which was prepared for comparison by electropolymerization of Pyr- $\mathrm{NO}_{2}$ on a Pt disc, shows enhanced background absorption due to the fluorescent effect, while two strong and broad peaks also appeared. A strong peak at 


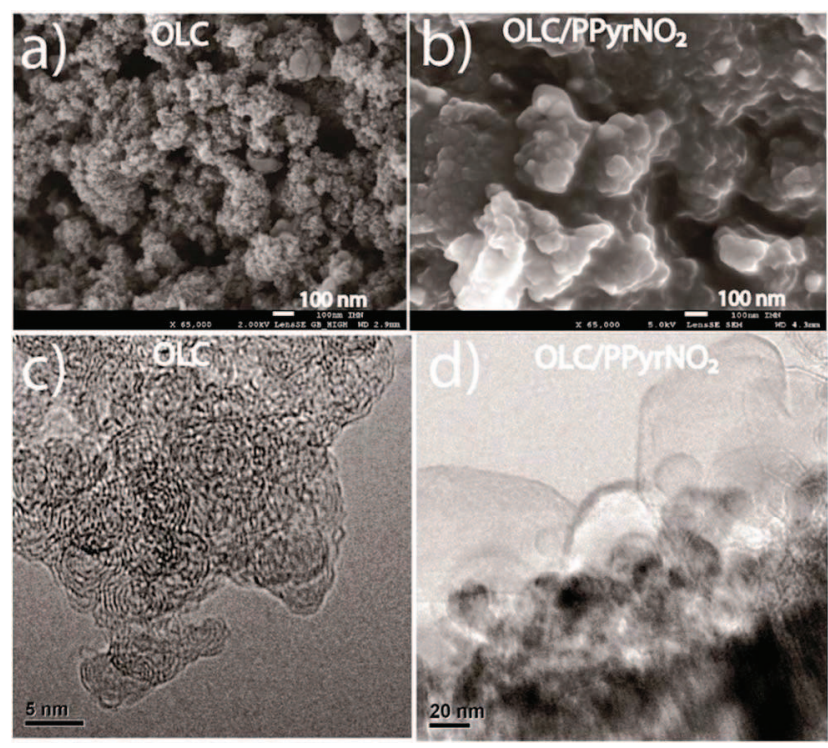

Fig. 3 SEM images of: (a) bare OLC; (b) PPyr- $\mathrm{NO}_{2}$-coated OLC after electro-polymerization and TEM of (c) bare OLC; (d) PPyr- $\mathrm{NO}_{2}$-coated OLC after electro-polymerization.
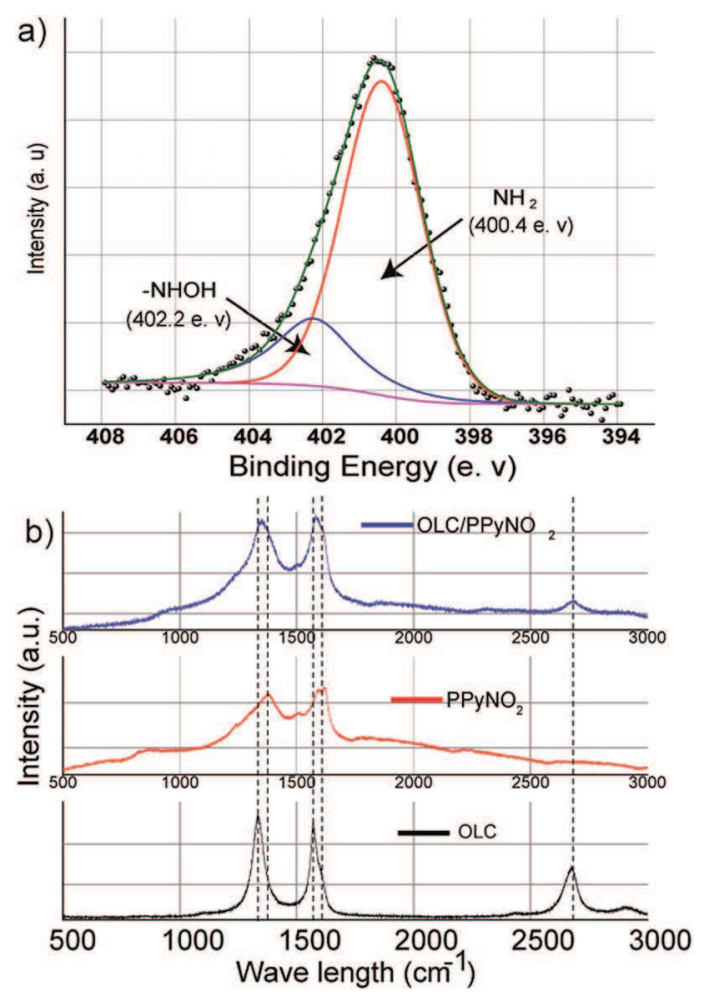

Fig. 4 (a) N1s core XPS spectra of PPyr- $\mathrm{NO}_{2}$-coated OLC after electro-polymerization. (b) Raman spectra of OLC, electro-polymerized $\mathrm{PyNO}_{2}$ on $\mathrm{Pt}$ disc and OLC/PPy- $\mathrm{NO}_{2}$.

$1377 \mathrm{~cm}^{-1}$ corresponds to the symmetric stretching of $\mathrm{N}-\mathrm{O}$ issuing from the $\mathrm{NHOH}^{38}$ Meanwhile, the second peak appeared to be a combination of two peaks at a frequency of 1620 and $1593 \mathrm{~cm}^{-1}$, which corresponds to the $\mathrm{C}-\mathrm{C}$ stretching of pyrene..$^{38,39}$ In case of OLC/Pyr- $\mathrm{NO}_{2}$, the background- enhanced spectrum is dominated by the polymer, though it is less prominent when compared to pure $\mathrm{PPyr}-\mathrm{NO}_{2}$. This confirms the nearly complete coverage of the carbon surface by PPyr- $\mathrm{NO}_{2}$, thus impeding D and $\mathrm{G}$ signals from the inner carbon surface, and we speculate that the trace signals are probably merged into the strong peaks of the polymer. However, a trace of the $2 \mathrm{D}$ band confirms the presence of carbon onion in the sample. Interestingly, the peak at $1377 \mathrm{~cm}^{-1}$ is found to be red shifted to $1348 \mathrm{~cm}^{-1}$, while other bands are found to be unaffected and indicating the interaction of $\mathrm{NO}_{2}$ with the carbon surface, as reported elsewhere. ${ }^{40}$

The improvement of the overall capacity of OLC/PPy- $\mathrm{NO}_{2}$ is found to reach a plateau after 1000 cycles, presumably because electron transfer through the polymer layer becomes increasingly hindered. Interestingly, extended cycling shows that the redox activity remains remarkably stable for more than 4000 cycles (Fig. 1d). UV spectroscopy of the electrolyte shows a decreasing concentration of $\mathrm{Py}^{-\mathrm{NO}_{2}}$ from $2 \mathrm{mM}$ to $0.65 \mathrm{mM}$, indicating a coverage of $1.6 \times 10^{-10} \mathrm{~mol} \mathrm{~cm}^{-2}$. In order to examine the range of possible grafting yield of the $\mathrm{Pyr}-\mathrm{NO}_{2}$ onto OLC, polymerization was carried out with a higher concentration of Pyr- $\mathrm{NO}_{2}$ in LP-30. A grafting of 27 and $43 \mathrm{wt} \%$ were measured in the case of 5 and $10 \mathrm{mM}$ Pyr- $\mathrm{NO}_{2}$ in LP-30 respectively, after 500 cycles of $\mathrm{CV}$ at a scan rate of $5 \mathrm{mV} \mathrm{s}^{-1}$. The $\mathrm{CV}$ profiles, compared in Fig. 5a, clearly illustrate the fact that a larger polarization appears above $20 \mathrm{wt} \%$ coverage. As regards the $20 \mathrm{wt} \%$ grafting, the capacity of the OLC electrode improves from $20 \mathrm{~mA} \mathrm{~h}$ gelectrode $^{-1}$ to $47 \mathrm{~mA} \mathrm{~h} g_{\text {electrode }}{ }^{-1}$, (i.e. $+90 \%$ ) (Fig. 5c).

In order to confirm the superior role of graphitization over SSA towards the $\pi$-stacking and $\mathrm{NO}_{2}$ reduction, a controlled experiment was carried out with highly porous carbon (YP-80 and microporous carbon from ACS chemicals). Even though

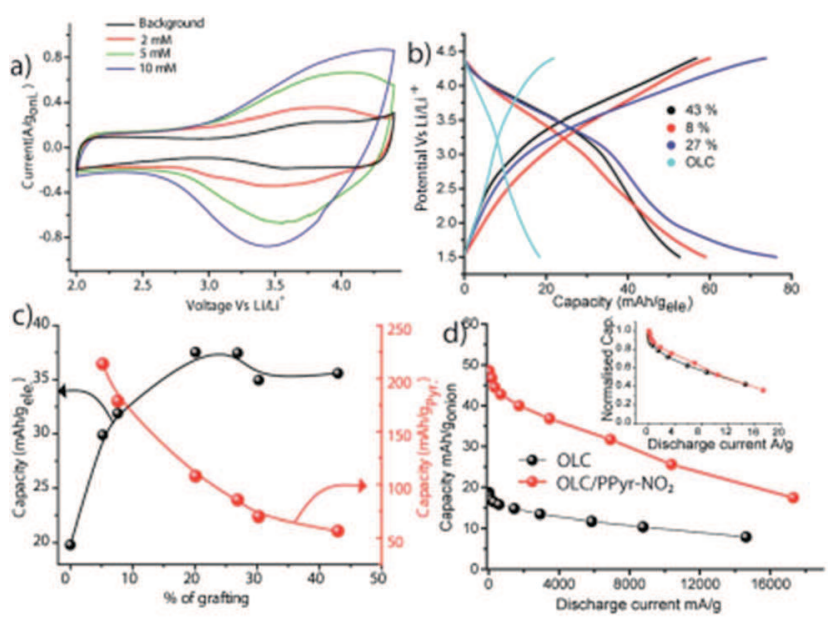

Fig. 5 (a) $400^{\text {th }} \mathrm{CV}$ profile at a scan rate of $5 \mathrm{mV} \mathrm{s}^{-1}$ in LP-30 containing 2-10 mM Pyr- $\mathrm{NO}_{2}$. (b) Charge-discharge plots at a current density of $0.1 \mathrm{~mA} \mathrm{~cm} \mathrm{~cm}^{-2}$ of the OLC and its composites containing grafted PPy- $\mathrm{NO}_{2}$, where the $y$-axis is normalized with the total mass of the electrode (OLC + PPyr- $-\mathrm{NO}_{2}$ ). (c) Capacity of the total electrode and PPy- $\mathrm{NO}_{2}$ with varying amounts of grafting. (d) Capacity of the OLC and the $20 \%$ grafted OLC with different current densities. The normalized capacity change is depicted in the inset. 
porous carbon possesses SSA over $2000 \mathrm{~m}^{2} \mathrm{~g}^{-1}$, a negligible $\mathrm{NO}_{2}$ reduction is observed due to poor $\pi$-stacking, and results in polymerization was carried out with a higher concentration of Pyr- $\mathrm{NO}_{2}$ in LP-30 (Fig. S5 $\dagger$ ). Thus, the higher capacity of the Pyr- $\mathrm{NO}_{2}$ samples arises from three factors: (i) better $\pi$-stacking ability, as proved by the UV sorption studies; (ii) lower oxidation potential after reduction of $\mathrm{NO}_{2}$ functionalities, both contributing to enhancing the grafting yield; and (iii) two redox reactions (associated with the reduced $\mathrm{NO}_{2}$ and the pyrene polymer). In order to validate this theory, Pyr- $\mathrm{NO}_{2}$ was cycled with a cut-off discharge potential of $3 \mathrm{~V}$, which thereby prevents the reduction of the nitro groups. As expected, the onset of the polymerization occurs at a higher potential $(4.33 \mathrm{~V})$, but more importantly, the capacity improvement is found to be greatly reduced compared to that corresponding to the $2 \mathrm{~V}$ cut-off potential (ESI Fig. S6 $\dagger$ ). XPS analysis of the above electrode after 800 cycles indicate only a partial reduction of $-\mathrm{NO}_{2}$ groups. A strong peak at $406 \mathrm{eV}$ of N1s XPS in Fig. S7† even after long cycles confirms this fact. As for the two other derivatives, the capacity of the OLC functionalized with $\mathrm{Pyr}-\mathrm{NH}_{2}$ is superior to that of pure pyrene. This difference can thus be ascribed in part to the lower oxidation onset potential of $\mathrm{Pyr}-\mathrm{NH}_{2}$, which helps to gain a higher amount of grafted Pyr- $\mathrm{NH}_{2}$ molecules (10 wt\% grafting).

The relation between the capacity per mass of the overall electrode and that of grafted $\mathrm{Pyr}-\mathrm{NO}_{2}$ is given in Fig. 5c. A maximum $214 \mathrm{~mA} \mathrm{~h} \mathrm{~g}^{-1}$ is obtained for Pyr- $\mathrm{NO}_{2}$ at a grafting coverage of $5 \mathrm{wt} \%$. However, as the grafting coverage increases, the capacity associated with the Pyr- $\mathrm{NO}_{2}$ group decreases, which is presumably due to hindered mass transport within the porosity of the polymer. In order to utilize this in situ grafting strategy in a practical full cell, a high power density negative electrode is also under consideration. This is expected to replace the conventional $\mathrm{Li}$, lithium titanate and pre-lithiated graphite negative electrodes.

The Nyquist plot in Fig. $88 \dagger$ demonstrates that, even after 1000 cycles and a two-fold increase in the capacity of the OLC, there is only a slight rise in the charge transfer resistance in the case of the $20 \mathrm{wt} \%$ sample. By comparison, adding redox capacity to carbon by a conventional molecule mixture or covalent grafting is expected to lower the power density due to: (i) poor $\mathrm{e}^{-}$percolation through the carbon particle, since carbon particles are separated by the grafted molecules and by $\mathrm{sp}^{3}$ defects of carbon as a result of grafting; and (ii) poor mass transport within the porosity of the molecular layer. By virtue of the present in situ grafting strategy, we are able to overcome the above constraints, as evidenced by the fact that the OLC architecture remains intact even after grafting, and that the kinetics improves. Indeed, as shown in Fig. 5d, the power characteristics of the electrode with $20 \mathrm{wt} \%$ grafting is similar to that of the bare OLC electrode. Even at a current density of $10 \mathrm{~A} \mathrm{~g}^{-1}$ $\left(28 \mathrm{~mA} \mathrm{~cm}^{-2}\right)$, half of the capacity is retained. Interestingly, the decrease in capacity with respect to higher current density is similar to that of bare OLC (Fig. 5d), demonstrating that in situ grafting as high as $20 \mathrm{wt} \%$ does not have any impact on the power characteristics. This result is in line with the $R_{\mathrm{ct}}$ data from the EIS (Fig. S8 $\dagger$ ). Self-discharge characteristics were evaluated by monitoring the voltage drop for 10 hours upon charging the cell to $4.4 \mathrm{~V}$. For both the blank OLC and $\mathrm{OLC} / \mathrm{PPy}-\mathrm{NO}_{2}$ the final potential was $4.1 \mathrm{~V}$. Interestingly however, the capacity recovered during the subsequent discharge was decreased by $7.6 \%$ for the grafted sample compared to $11 \%$ for the blank OLC which further demonstrates the advantage incurred by redox grafting of carbon electrodes.

\section{Conclusion}

In summary, we have developed a simple strategy for grafting Pyr- $\mathrm{NO}_{2}$ molecules onto highly graphitized OLC via $\pi$-stacking, in situ reduction and a further polymerization of pyrene moieties at low potential. This approach facilitates the attainment of a high mass polymer loading, which results in an enhanced electrode redox capacity: when compared to $\mathrm{Pyr}-\mathrm{NH}_{2}$, pyrene and even unreduced Pyr- $\mathrm{NO}_{2}$, this demonstrates the key role of the redox activity coupled with the reduced $\mathrm{NO}_{2}$ moiety, which is functionalized on the OLC backbone. DFT calculations demonstrate the charge transfer and binding enthalpy capabilities of Pyr- $\mathrm{NO}_{2}$, which are significantly higher than those of the other two species, and which allow for improved p-stacking on the carbon surface. A $20 \mathrm{wt} \%$ grafting of Pyr- $\mathrm{NO}_{2}$ enables a nearly two-fold increase in the capacity of the entire electrode from $20 \mathrm{~mA} \mathrm{~h}$ gelectrode $^{-1}$ to $38 \mathrm{~mA} \mathrm{~h} \mathrm{~g}_{\text {electrode }}{ }^{-1}$, while the average potential is increased by $200 \mathrm{mV}$. Under these conditions, the resulting grafted polymer shows a capacity of $110 \mathrm{~mA} \mathrm{~h} \mathrm{~g}{ }^{-1}$. Most importantly, the capacity retention is maintained for more than 4000 cycles without changing either the electrolyte or the Li counter electrode. The power characteristics of the bare OLC are also sustained, which further demonstrates the substantial advantages incurred by adopting the proposed controlled in situ grafting technique.

\section{Acknowledgements}

BA, TB and JG acknowledge the financial assistance provided by the Agence Nationale de la Recherche (ANR) Project No. 13-PRGE-0011 and the French Research Network on Electrochemical Energy Storage (RS2E).

\section{References}

1 Z. Yang, J. Zhang, M. Kintner-Meyer, X. Lu, D. Choi, J. Lemmon and J. Liu, Chem. Rev., 2011, 111, 3577-3613.

2 P. Simon and Y. Gogotsi, Nat. Mater., 2008, 7, 845-854.

3 B. E. Conway, Electrochemical Supercapacitors: Scientific Fundamentals and Technological Applications, Springer, 1999.

4 L. L. Zhang and X. S. Zhao, Chem. Soc. Rev., 2009, 38, 25202531.

5 D. Belanger and J. Pinson, Chem. Soc. Rev., 2011, 40, 39954048.

6 L. Madec, A. Bouvree, P. Blanchard, C. Cougnon, T. Brousse, B. Lestriez, D. Guyomard and J. Gaubicher, Environ. Sci. Technol., 2012, 5, 5379-5386. 
7 L. Madec, D. Robert, P. Moreau, P. Bayle-Guillemaud, D. Guyomard and J. Gaubicher, J. Am. Chem. Soc., 2013, 135, 11614-11622.

8 E. Lebegue, T. Brousse, J. Gaubicher, R. Retoux and C. Cougnon, J. Mater. Chem. A, 2014, 2, 8599-8602.

9 Y. Li, Z. Jian, M. Lang, C. Zhang and X. Huang, ACS Appl. Mater. Interfaces, 2016, 8, 17352-17359.

10 W. Choi, S. Endo, K. Oyaizu, H. Nishide and K. E. Geckeler, J. Mater. Chem. A, 2013, 1, 2999-3003.

11 A. Borenstein, S. Hershkovitz, A. Oz, S. Luski, Y. Tsur and D. Aurbach, J. Phys. Chem. C, 2015, 119, 12165-12173.

12 K. W. Leitner, B. Gollas, M. Winter and J. O. Besenhard, Electrochim. Acta, 2004, 50, 199-204.

13 J. Chmiola, G. Yushin, Y. Gogotsi, C. Portet, P. Simon and P. L. Taberna, Science, 2006, 313, 1760-1763.

14 A. Rudge, J. Davey, I. Raistrick, S. Gottesfeld and J. P. Ferraris, J. Power Sources, 1994, 47, 89-107.

15 G. Wang, L. Zhang and J. Zhang, Chem. Soc. Rev., 2012, 41, 797-828.

16 T. Janoschka, M. D. Hager and U. S. Schubert, Adv. Mater., 2012, 24, 6397-6409.

17 H. Nishide, S. Iwasa, Y.-J. Pu, T. Suga, K. Nakahara and M. Satoh, Electrochim. Acta, 2004, 50, 827-831.

18 R. J. Waltman and J. Bargon, Can. J. Chem., 1986, 64, 76-95.

19 J. C. Bachman, R. Kavian, D. J. Graham, D. Y. Kim, S. Noda, D. G. Nocera, Y. Shao-Horn and S. W. Lee, Nat. Commun., 2015, 6, 7040.

20 C. A. Hunter and J. K. M. Sanders, J. Am. Chem. Soc., 1990, 112, 5525-5534.

21 D. Zhu and J. J. Pignatello, Environ. Sci. Technol., 2005, 39, 2033-2041.

22 S. Iijima, J. Cryst. Growth, 1980, 50, 675-683.

23 C. Portet, G. Yushin and Y. Gogotsi, Carbon, 2007, 45, 25112518.

24 J. K. McDonough, A. I. Frolov, V. Presser, J. Niu, C. H. Miller, T. Ubieto, M. V. Fedorov and Y. Gogotsi, Carbon, 2012, 50, 3298-3309.

25 D. Pech, M. Brunet, H. Durou, P. Huang, V. Mochalin, Y. Gogotsi, P.-L. Taberna and P. Simon, Nat. Nanotechnol., 2010, 5, 651-654.
26 D. A. G. Bruggeman, Ann. Phys., 1935, 416, 636-664.

27 I. V. Thorat, D. E. Stephenson, N. A. Zacharias, K. Zaghib, J. N. Harb and D. R. Wheeler, J. Power Sources, 2009, 188, 592-600.

28 X. Yang, C. Cheng, Y. Wang, L. Qiu and D. Li, Science, 2013, 341, 534-537.

29 L. Madec, K. A. Seid, J. C. Badot, B. Humbert, P. Moreau, O. Dubrunfaut, B. Lestriez, D. Guyomard and J. Gaubicher, Phys. Chem. Chem. Phys., 2014, 16, 22745-22753.

30 L. Madec, B. Humbert, B. Lestriez, T. Brousse, C. Cougnon, D. Guyomard and J. Gaubicher, J. Power Sources, 2013, 232, 246-253.

31 C. Hansch, A. Leo and R. W. Taft, Chem. Rev., 1991, 91, 165195.

32 J. Heinze, J. Mortensen and M. Störzbach, in Electronic Properties of Conjugated Polymers: Proceedings of an International Winter School, Kirchberg, Tirol, March 14-21, 1987, ed. H. Kuzmany, M. Mehring and S. Roth, Springer Berlin Heidelberg, Berlin, Heidelberg, 1987, pp. 385-390, DOI: 10.1007/978-3-642-83284-0_71.

33 P. Allongue, M. Delamar, B. Desbat, O. Fagebaume, R. Hitmi, J. Pinson and J.-M. Savéant, J. Am. Chem. Soc., 1997, 119, 201207.

34 S. S. C. Yu, E. S. Q. Tan, R. T. Jane and A. J. Downard, Langmuir, 2007, 23, 11074-11082.

35 J. I. Paez, M. C. Strumia, M. C. G. Passeggi Jr, J. Ferrón, A. M. Baruzzi and V. Brunetti, Electrochim. Acta, 2009, 54, 4192-4197.

36 G. Shul, C. A. C. Ruiz, D. Rochefort, P. A. Brooksby and D. Bélanger, Electrochim. Acta, 2013, 106, 378-385.

37 D. Roy, M. Chhowalla, H. Wang, N. Sano, I. Alexandrou, T. W. Clyne and G. A. J. Amaratunga, Chem. Phys. Lett., 2003, 373, 52-56.

38 P. D. Enlow and T. Vo-Dinh, Anal. Chem., 1986, 58, 11191123.

39 H. Shinohara, Y. Yamakita and K. Ohno, J. Mol. Struct., 1998, 442, 221-234.

40 Q. Li, Q. Xue, L. Hao, X. Gao and Q. Zheng, Compos. Sci. Technol., 2008, 68, 2290-2296. 